\title{
História dos Direitos da Criança no mundo e em Moçambique: um estudo sobre a sua evolução
}

\author{
History of Children's Rights worldwide and in Mozambique: a study on \\ its evolution
}

http://dx.doi.org/10.5007/2178-4582.2016v50n1p64

Tomás Xavier José Francisco

Polícia da República de Moçambique, Tete/Tete, Moçambique

\begin{abstract}
O presente trabalho de pesquisa analisa a evolução da história dos direitos da criança no mundo e em Moçambique. $\mathrm{O}$ artigo evidencia o longo e tortuoso caminho percorrido até que se adotasse um quadro legal favorável à promoção e proteção dos direitos da criança no mundo, em geral, e em Moçambique, em particular. A metodologia utilizada foi a revisão bibliográfica, antecedida por um inicial estudo exploratório.
\end{abstract}

Palavras-chave: História da Criança. Direitos da Criança. Direitos da Criança em Moçambique.
This research work analyzes the evolution of the history of children's rights in the world and in Mozambique. The article highlighted the long and tortuous path followed until it is adopt a legal framework favorable to the promotion and protection of children's rights in the world in general and in Mozambique in particular. The methodology used was a literature review, preceded by an initial exploratory study.

Keywords: Child's History. Children's rights. Children's rights in Mozambique.

\section{Introdução}

Ao longo da história da humanidade nem sempre a criança foi objeto de atenção especial e interesse por parte da sociedade. Houve períodos em que a consciência social não admitia a existência autônoma da infância como categoria diferenciada do gênero humano. Entretanto, a partir do Século XX, a sociedade começa a reconhecer, com sinais muitos claros e evidentes, a criança como um ator social e detentora ativa dos seus próprios direitos. Desta forma, a infância torna-se uma questão central para a sociedade.

O presente trabalho de pesquisa tem como objetivo analisar a evolução da história dos direitos da criança no mundo e em Moçambique. Ao longo do trabalho se demonstra o período em que a sociedade não dava muita atenção aos temas da infância. Igualmente demonstra-se o momento em que a criança se tornou objeto de maior interesse e um ator válido pela sociedade. Também se demonstra no estudo o papel desempenhado pelas diversas ONGs internacionais e estudiosos nos debates e estudos que culminaram com a adoção de normas internacionais que, por sua vez, tornaram a criança, um sujeito de direitos.

Para a materialização do estudo, a metodologia utilizada foi a revisão bibliográfica, que consistiu no levantamento de referências teóricas publicadas 
por meios impressos e eletrônicos, como livros, artigos científicos e paginas on-line. Importa referir que essa revisão bibliográfica foi antecedida por um inicial estudo exploratório.

\section{História dos Direitos da Criança no mundo}

$\mathrm{Na}$ atualidade, não se pode falar da criança ou dos seus direitos sem recorrer-se ao passado para perceber como ela era tratada. É preciso recorrer, por exemplo, à Idade Média para se ter alguma ideia de como a sociedade daquela época tratava as suas crianças. "Longo tem sido o percurso histórico das instituições sociais, inclusive jurídicas e acadêmicas, para que os adultos das sociedades ocidentais reconhecessem, à criança, o estatuto de sujeito e a dignidade de pessoa." (ROSEMBERG; MARIANO, 2010, p. 694).

Dentre os marcos fundantes desse reconhecimento destacam-se a Declaração Universal dos Direitos da Criança, promulgada pela ONU (Organização da Nações Unidas), em 1959, e a publicação do livro de Philippe Ariès (1961), L'enfant et la vie familiale sou l'ancien régime. Apesar de críticas que lhes foram feitas, ambos os textos instalaram discursos e práticas sobre a infância e as crianças contemporâneas (ROSEMBERG; MARIANO, 2010, p. 694)

Ao longo da história, o processo de atendimento à criança ocorreu de diversas formas. Diferentemente do quadro atual em que se assiste uma grande preocupação, em relação à criança, registraram-se momentos em que a sociedade dava menos atenção ao sentimento da infância e não dispensava um tratamento especial às crianças. Na Idade Média, por exemplo, está situação foi mais visível. De acordo com Ariès, "Até por volta do século XII, a arte medieval desconhecia a infância ou não tentava representá-la. É difícil crer que essa ausência se devesse à incompetência ou à falta de habilidade. É mais provável que não houvesse lugar para a infância nesse mundo" (1981, p. 17).

Nesse século e nos outros seguintes, principalmente ao longo do Século XIII, a criança era vista apenas como uma combinação biológica, não como um sujeito histórico e cultural, com certo espaço conquistado ao nível da sociedade. Ainda segundo Ariès, "Embora exibisse mais sentimento ao retratar a infância, o século XIII continuou fiel a esse procedimento. Na Bíblia moralizada de São Luís, as crianças são representadas com maior frequência, mas nem sempre são caracterizadas por algo além de seu tamanho" (Ibid., p. 17).

Esse cenário prevaleceu nos séculos subsequentes até o século XVII, quando o sentimento da criança é representado por ela mesma, tornando esse século como o aquele que promove uma grande alteração no que se refere à criança. 
O leitor destas páginas sem dúvidas terá notado a importância do Século XVII na evolução dos temas da primeira infância. Foi no século XVII que os retratos de crianças sozinhas se tornaram numerosos e comuns. Foi também nesse século que os retratos de família, muito mais antigos, tenderam a se organizar em torno da criança, que se tornou o centro da composição (ARIÈS, 1981, p. 28).

A aparição da infância ocorreu em torno do Século XIII e XIV, mas os sinais de sua evolução tornaram-se claros e evidentes, no continente europeu, entre os Séculos XVI e XVII, ou seja, no momento em que a estrutura social vigente (mercantilismo) provocou uma alteração nos sentimentos e nas relações frente à infância (CARVALHO, 2003, p. 47).

Foi a partir desse século que a sociedade começa a dar maior atenção aos sentimentos da infância. Aos poucos, a criança começa a ganhar espaço na sociedade e já começa a ser representada, não só com certa frequência, como também, como sujeito; e caracterizada, para além do seu tamanho, como acontecera, nos séculos anteriores.

Obviamente, isto não significa negar a existência biológica desses indivíduos. Significa, em realidade, reconhecer que, antes do Século XVI, a consciência social não admite a existência autônoma da infância como uma categoria diferenciada do gênero humano. Passado o estrito período de dependência física da mãe, esses indivíduos se incorporavam plenamente ao mundo dos adultos (LEVIN, 1997).

No século XVIII, com a eclosão da Revolução Industrial, continua a criança a ganhar cada vez mais espaço, apesar de que, nesse mesmo século, a criança continua a atravessar momentos difíceis em termos da sua sobrevivência.

No Século XIX, a situação sobre o sentimento da infância continuou a evoluir. As políticas de atendimento à criança e ao adolescente desenvolveram-se no decorrer da história marcadas pela caracterização que esses sujeitos adquiriram na sociedade, caracterização que foi influenciada pelos sentidos produzidos por diferentes áreas de conhecimento. A materialidade de problemas da ordem social vivenciados pela infância e juventude levou, e ainda leva, à produção de saberes, de leis e de intervenções médicas, jurídicas e sociais que remontam o fim do século XIX (SARTÓRIO, 2007, p. 25).

Mas, em termos concretos, foi só a partir do final do Século XX que a infância tornou-se uma questão central para a sociedade. De acordo com Fiuza, Sila e Sonego, 2010), Barroso afirma que:

[o] século XX foi marcado pelas grandes invenções tecnológica, pelas inigualáveis descobertas científicas, pelas devastado- 
ras guerras civis e mundiais, gerando profundas mudanças nas sociedades humanas, mas foi, fundamentalmente, o século da descoberta da criança como um sujeito de direitos (2000, p. 77).

Mas antes, no início do século XX, surge uma movimentação em torno da concepção de uma justiça voltada para menores. Os Estados Unidos da Américas são os primeiros a promover uma reforma radical na assistência judiciária ao menor, através da instituição do julgamento de crianças em tribunais especiais. Nessa época, experiências inovadoras surgiram em Boston e Chicago, cidades consideradas verdadeiros laboratórios do crime (SILVA, 2011, p. 3637). Em Boston foram identificadas as primeiras tentativas de aplicação do regime de liberdade fiscalizada' (probation) no ano de 1869. E, em Chicago, foi instalado o primeiro Tribunal para crianças' (Children 's Court), em 1899. Essas iniciativas foram seguidas em grande parte dos estados americanos, e em diversos países da Europa ainda no século XIX (RIZZINI, 1997, p. 219 apud SILVA, 2011, p. 37, grifos da autora).

Por outro lado, a realização, em 1911, do Congresso Internacional de Menores em Paris e a Declaração de Gênova dos Direitos da Criança, que foi adotada pela Liga das Nações em 1924, foram dois episódios, em nível mundial, fundamentais para afirmação do Direito do Menor, constituindo-se os primeiros instrumentos internacionais a reconhecerem a ideia de um Direito da Criança (SILVA, 2011, p. 37).

\footnotetext{
Essa afirmação se complementa ao percebermos que, logo nas primeiras décadas do século XX, fizeram-se presentes, no cenário mundial, reuniões internacionais (realizadas em Genebra, em 1924, e em Viena, no ano de 1952) que tinham como objetivo maior discutir e buscar meios que possibilitasse garantir o bem-estar das crianças em todo o mundo; posteriormente, esta discussão foi ampliada e reafirmada com a Declaração dos Direitos da Criança, aprovada em 1959, e, com Convenção sobre os Direitos da Criança e do Adolescente, em 1989. (FIUZA; SILA; SONEGO, 2010, p. 85).
}

Fato notável igualmente nesse período foi o aparecimento de muitas ONGs, como a Save the Children. De forma substancial, essas instituições supragovernamentais pressionaram os governos de todo mundo para que adotassem medidas, com vistas à proteção dos direitos da criança. Por isso, assistimos neste século, a aprovação de uma boa parte dos instrumentos legais internacionais que versam sobre a matéria da criança na atualidade. Muitos países incorporaram, por exemplo, a Convenção sobre os Direitos da Criança à sua legislação nacional, bem como os códigos relacionados à criança, baseados nos dispositivos da Convenção. "A legislação internacional marcará o 
início da nova concepção da criança como sujeito do processo, titular de direitos e obrigações próprias da sua condição de pessoa em desenvolvimento" (SILVA, 2011, p. 39).

Outro marco importante que torna o Século XX um século de uma nova concepção sobre a infância, foi a publicação do livro de Philippe Ariès, autor a quem já fizemos referência anteriormente. Falando sobre o contributo da obra de Philippe Ariès, na área de infância, Rosemberg e Mariano, afirmam o seguinte:

\begin{abstract}
Ariès (1961), ao inaugurar a visão da infância como uma construção social, dependente ao mesmo tempo do contexto social e do discurso intelectual' (Sirota, 2001, p. 10), lança as bases para a mudança pragmática proposta, nas décadas de 1980 e 1990, pelos Estudos Sociais sobre a Infância (na tradição anglosaxônica), ou Sociologia da Infância (na tradição francófona) (ROSENBERG; MARIANO, 2010, p.694).
\end{abstract}

Trata-se de alçar a infância à condição de objeto legítimo das Ciências Humanas e Sociais; entender a infância como uma construção social; romper com o modelo 'desenvolvimentalista' da Psicologia (por exemplo, o piagetiano) impelido para uma estrutura de racionalização adulta permanentemente definida'(JENKS, 2002, p. 2012); atacar o conceito de socialização da criança como inculcação, até então predominante na Antropologia, na Psicologia e na Sociologia; conceber a criança como ator social (ROSEMBERG; MARIANO, 2010, p. 694). Segundo estas autoras, "Essa nova perspectiva de compreensão da infância rompeu com tendência principais então vigentes na produção teórica e no contexto sociopolítico de discursos e práticas referentes à infância e que envolve crianças" (Ibid., p. 694).

A nova produção teórica foi angariando adeptos, inicialmente nos países do hemisfério norte, tendo sido reconhecida como campo legítimo de produção acadêmica em 1990, quando a Internacional Sociological Association criou um grupo de trabalho sobre a Sociologia da Infância. Ela também informou discussões sobre direitos da criança que percorreram as décadas de 1970 e 1980 (Ibid., p. 695).

Na história dos direitos da criança, não se pode falar dos esforços na promoção e proteção direitos das crianças, sem se fazer menção à Organização das Nações Unidas (ONU) - ou Nações Unidas (NU) - principalmente do papel preponderante que esse organismo internacional desempenhou, e continua a desempenhar, na adoção de um quadro legal favorável em todos seus Estadosmembros que contribua para a promoção e proteção dos direitos da criança.

Importa mencionar que, antes da criação da ONU, vigorou em nível internacional, outra organização que abriu caminho aos esforços de promoção 
e proteção dos direitos das crianças: a Sociedade das Nações ${ }^{1}$ (SDN), ou Liga das Nações, criada no ano de 1919 e autodissolvida em 1946, após a eclosão da segunda Guerra Mundial em 1939. Em matéria de proteção dos direitos da criança, a SDN foi pioneira, através da OIT (Organização Internacional de Trabalho) - na altura, uma agência instituída pela SDN, após a assinatura do Tratado de Versalhes (1919). A OIT concentrou suas convenções iniciais na garantia dos direitos de trabalhadores infantis, como na convenção sobre o Trabalho Noturno dos Adolescentes (Indústria), de 1919; e a Convenção sobre Idade Mínima (Agricultura) (OIT, 1919 apud UNICEF, 2009, p. 4). O conjunto das normas e recomendações da OIT se divide em vários temas, dentre eles, se destaca o trabalho de Menores.

Por sua vez, em 26 de Setembro de 1924, a própria SDN adota e aprova a Carta da Liga sobre as Crianças, documento igualmente conhecido como a Declaração de Genebra. Em 1924, a Liga das Nações adota a Declaração de Genebra sobre os Direitos da Criança. A Declaração estabelece os direitos da criança aos meios para o seu desenvolvimento material, moral e espiritual; ajuda especial em situações de fome, doença, incapacidade ou orfandade; prioridade no atendimento em situações difíceis; imunidade contra exploração econômica; e educação em um ambiente que inspire um sentido de responsabilidade social.

Importa frisar sobre direitos da criança que, no panorama internacional, destaque também vai para o trabalho desenvolvido por Eglantyne Jebb, a fundadora da Save the Children. De acordo com o Unicef, "A primeira conceituação formal de direitos da criança elaborada pelas organizações internacionais nascentes derivou do trabalho de Eglantyne Jebb que, em 1919, fundou na Inglaterra o Save the Children, e estabeleceu em Genebra, no ano seguinte, a União Save the Children Internacional". Segundo o Comité Internacional da Cruz Vermelha (1963, apud UNICEF, 2009, p. 4), "O Save the Children foi fundado para levantar recursos para ajuda de emergência para crianças que sofriam as consequências da Primeira Guerra Mundial"

Em 1923, Jebb afirmou sua posição com relação aos direitos da criança na seguinte declaração: Para mim, parece chegado o momento em que já não se pode mais esperar que grandes ações de alívio sejam realizadas. Se mesmo assim quisermos continuar trabalhando pela criança [...], aparentemente o único meio para fazê-lo é conclamar um esforço cooperativo das nações para proteger suas próprias crianças de maneira construtiva, e não como caridade. Acredito que devemos reclamar certos direitos para a criança e trabalhar para que sejam reconhecidos internacionalmente (Ibid., p. 4).

\footnotetext{
1 Organização criada pelas potências vencedoras da Primeira Guerra Mundial, com fim de assegurar a paz
} mundial, tendo sido dissolvida por não ter cumprido com esse objetivo, com a eclosão da Segunda Guerra Mundial. 
Com esse objetivo, a União Save the Children Internacional elaborou a proposta preliminar de uma declaração sucinta que reivindicava direitos para a criança, e convenceu a Liga das Nações a adotá-la na Declaração de Genebra dos Direitos da Criança, em 26 de Setembro de 1924 (Id.,Ibid.).

Como se disse anteriormente, esses esforços iniciais sobre os direitos da criança conhecem outro rumo com a criação da ONU/NU, em 24 de Outubro de 1945, na Cidade de São Francisco- Califórnia- EUA, após a Segunda Guerra Mundial. Logo após a sua fundação, a ONU sofre a primeira pressão em matéria de criança, no que tange à Declaração de Genebra. Em 1946, a União Internacional para o Bem-estar da Criança (Internacional Union for Child Welfare- IUCW)- uma fusão entre a União Save the Children Internacional e a Associação Internacional para o Bem-estar da Criança, estabelecida em Bruxelas- pressionou a Organizações das Nações Unidas a endossar a Declaração de Genebra (UNICEF, 2009, grifo do autor).

Desde a sua criação, em 1945, um dos principais objetivos da ONU foi de apoiar e de proteger os mais vulneráveis e oprimidos. O primeiro parágrafo da Carta das Nações Unidas expressa a determinação dos povos ao redor do mundo de promover o progresso social e melhores condições de vida dentro de uma liberdade ampla', e de 'empregar um mecanismo internacional para promover o progresso econômico e social de todos os povos'(RIBEIRO, 2011).

$\mathrm{O}$ artigo 55 amplia esses propósitos, afirmando que as Nações Unidas favorecerão níveis mais altos de vida, trabalho efetivo e condições de progresso e desenvolvimento econômico e social', e a solução dos problemas internacionais econômicos, sociais, de saúde e relacionados'. Provavelmente simbólico o fato de que o primeiro de todos estes encontros tenha sido voltado para as crianças (Ibid.).

A história dos instrumentos legais internacionais dos direitos da criança sob a égide da ONU começa no ano de 1948, com a aprovação da Declaração Universal dos Direitos Humanos (DUDH), pela Assembleia Geral da ONU. A aprovação dessa declaração abriu uma nova etapa na promoção e proteção dos direitos da criança, depois dos esforços iniciais empreendidos pela OIT, em 1919, e pela SDN quando, em 1924, adotou a Declaração de Genebra sobre os Direitos da Criança.

A aprovação desta declaração abriu uma etapa crucial na promoção e proteção dos direitos da criança. $\mathrm{O}$ artigo 25 faz menção ao direito da criança quando afirma que "A maternidade e a infância têm direito a ajuda e a assistência especiais. Todas as crianças, nascidas dentro ou fora do matrimônio, gozam da mesma proteção social" ( $\mathrm{n}^{\circ} .2$, do artigo 25 da DUDH - ONU, 1948). 
Dessa forma, a ONU dava primeiros sinais sobre o rumo que iria tomar na questão dos direitos da criança. E, em 20 de novembro de 1959, a Assembleia Geral da ONU adota a declaração dos Direitos da Criança. Segundo a UNICEF (2009, p. 5), o endosso da Assembleia Geral foi significativo porque colocou em evidência a necessidade de se considerar separadamente os direitos da criança, em vez de assumir que os cuidados com a criança estariam implícitos no amplo espectro dos instrumentos internacionais de direitos humanos. E, ainda, "A Declaração dos Direitos da Criança enfatizou de maneira especial o bem-estar emocional da criança e assegurou o seu direito a ser dos primeiros a receber proteção e alíviỏ (UNICEF, 2009).

No final da década de 1940, superada a Segunda Guerra, inicia-se mundialmente um processo de marcha pelos Direitos Humanos, destacando-se a Declaração Universal dos Direitos do Homem de 1948 e a Declaração dos Direitos da Criança de 1959, que constituem um marco fundamental no ordenamento jurídico internacional relativo aos direitos da criança e redundou na reformulação da Proteção Integral no final da década de 80 (SILVA, 2011, p. 39). Em suma, "Esta Declaração de 1959, sob os auspícios da Organização das Nações Unidas- ONU-, e a precedente, de 1924, conhecida como a Declaração de Genebra, sob os auspícios da Liga das Nações, tiveram como foco defender a idéia de proteção à criança" (RENAUT, 2002).

Em 1966 são adotados o Pacto Internacional sobre Direitos Civis e Políticos (PIDCP) e o Pacto Internacional sobre Direitos Econômicos, Sociais e Culturais (PIDESC). Os pactos advogam em favor da proteção da criança contra a exploração e promovem o direito à educação. Por exemplo, no Pacto Internacional sobre Direitos Civis e Políticos, no $\mathrm{n}^{\circ} .5$, do artigo 6 , salvaguarda-se a não aplicação de pena de morte aos menores de 18 anos e nem aplicada a mulher em caso de gravidez; no $\mathrm{n}^{\circ} .1$, artigo 14 , sobre a publicidade das sentenças em matéria penal e civil, chama-se atenção quando o interesse do menor exija procedimento oposto ou quando processo diga respeito a controvérsias matrimoniais ou à tutela de menores; igualmente nesse protocolo salvaguarda-se o direito da criança, sem descriminação alguma por motivo de cor, sexo, língua, religião, origem nacional ou social, situação econômica ou nascimento, às medidas de proteção que a sua condição de menor requer por parte da família, da sociedade e do Estado, a obrigação do seu registro e receber um nome, imediatamente após o seu nascimento e o de adquirir uma nacionalidade (n. ${ }^{\circ}$ s 1, 2, 3, do artigo 21, PIDCP, ONU, 1976a).

No Pacto Internacional sobre Direitos Econômicos, Sociais e Culturais, sobre a criança, o pacto ressalta a necessidade de adoção de medidas especiais de proteção e assistência em benefício de todas as crianças e adolescentes, sem discriminação alguma derivada de razões de paternidade ou outras, enfo- 
cando que crianças e adolescentes devem ser protegidos contra a exploração econômica e social. O emprego em trabalhos de natureza a comprometer a sua moralidade ou a sua saúde, capazes de pôr em perigo a sua vida, ou de prejudicar o seu desenvolvimento normal dever ser sujeito à sanção da lei. Os Estados devem também fixar os limites de idade abaixo dos quais, o emprego da mão-de-obra infantil será interdito e sujeito às sanções da lei. $\left(\mathrm{n}^{\circ} 3\right.$, do artigo 10, PIDESC, ONU, 1976b).

Seguidamente, em 1973, a Organização Internacional de Trabalho adota a Convenção $n^{\circ}$. 138, que trata da idade mínima para Admissão no Emprego, determinando em 18 anos a idade mínima para o trabalho que pode comprometer a saúde, a segurança ou a moral do indivíduo.

Para o efeito, levaram-se em consideração, dispositivos de varias convenções, dentre eles, a Convenção sobre a idade mínima (indústria), de 1919; a Convenção sobre a idade mínima (trabalho marítimo), de 1920; a Convenção sobre a idade mínima (agricultura), de 1921; a Convenção sobre a idade mínima (paioleiros e foguistas), de 1921; a Convenção sobre a idade mínima (trabalhos não industriais), de 1932; Convenção (revista) sobre a idade mínima (trabalho marítimo) de 1936; a Convenção (revista) sobre a idade mínima (industriais), de 1937; a Convenção (revista) sobre a idade mínima (trabalhos não industriais), de 1937; a Convenção sobre a idade mínima (pescadores), de 1959; e a Convenção sobre a idade mínima (trabalho subterrâneo), de 1965.

Depois, em 1979, a Assembleia Geral da ONU adota a Convenção sobre a Eliminação de Todas as Formas de Discriminação a Mulher, que garante proteção para os direitos humanos de meninas e mulheres. Além disso, declara 1979 como o Ano Internacional da Criança, colocando em ação o grupo de trabalho que elaboraria a versão preliminar de uma Convenção sobre os Direitos da Criança legalmente vinculante ${ }^{2}$.

Sobre o ano Internacional da criança, o seu objetivo foi o de focar atenções para os problemas que afetam as crianças em todo o mundo, como por exemplo, a desnutrição e a falta de acesso à educação. Vale destacar que, para esse feito, nota positiva vai para as ONGs que desempenharam um grande papel para que se declarasse o ano de 1979 como o ano Internacional da criança. Neste sentido, “As ONGs estimularam as nações Unidas a declarar 1979 como o Ano Internacional da Criança, em uma tentativa de chamar atenção para as questões que envolvem a infância" (UNICEF, 2009, p. 5).

Na convenção sobre a Eliminação de Todas as Formas de Discriminação contra a Mulher, os aspetos relacionados à criança aparecem refletidos em vá- 
rios dispositivos desta convenção, destacando-se na alínea c), do $\mathrm{n}^{\circ} .2$, do artigo 11, ao se salvaguardar que se estimule o fornecimento de serviços sociais de apoio necessários para permitir que os pais combinem as obrigações para com a família, com as responsabilidades do trabalho e a participação na vida pública, especialmente mediante o fomento da criação e desenvolvimento de uma rede de serviços destinados ao cuidado das crianças; na alínea f), do ${ }^{\circ}$. 1, do artigo 16, ao se prever que, em caso de guarda, tutela, curatela e adoção dos filhos ou institutos análogos, os interesses dos filhos serão a consideração primordial.

Posteriormente, ainda nesse esforço de busca de um quadro legal altamente favorável à promoção e proteção dos direitos da criança ao nível internacional, em 20 de novembro de 1989, a Assembléia Geral da ONU aprova por unanimidade a Convenção sobre os Direitos da Criança, que entra em vigor no ano seguinte, no dia 02 de Setembro de 1990.

Contudo, importa dizer que a aprovação desta convenção não se afigurou como uma tarefa fácil. Igualmente, as ONGs jogaram um papel importante para a aprovação desta Convenção, tida como a mais completa, no campo de promoção e proteção dos direitos da criança. "O projeto original da Convenção Internacional sobre os Direitos da Criança foi formalmente apresentado no começo de 1978, pelo governo polonês, à Comissão de Direitos Humanos da ONU, em homenagem a Januz Korczak" (CANTWELL, 1992, apud ROSEMBERG; MARIANO, 2010, p. 705). Segundo estes autores, "a previsão era que a Convenção fosse aprovada ao final de 1979, como um marco do Ano Internacional da Criança, que já havia mobilizado a sociedade internacional em prol de uma agenda para a infância” (Ibid.).

No entanto, a proposta inicial, encaminhada pelo secretariado Geral das Nações Unidas à apreciação dos países e organizações intergovernamentaisOIGs, recebeu muitas críticas, especialmente dos países ocidentais industrializados referente à sua linguagem imprecisa, omissões em relação a uma série de direitos e a sua implementação, item fundamental em tratado internacional (PILOTTI, 2000, p. 43 apud ROSEMBERG; MARIANO, 2010, p.705-706).

Para a Unicef, esse documento único define padrões internacionais para os cuidados, o tratamento e a proteção de todos os indivíduos com menos de 18 anos de idade. Constitui o tratado de direitos humanos mais amplamente endossado na história, ratificado hoje por 193 Estados-Parte. Ainda sobre a sua aceitação e a importância dessa convenção, a Unicef destaca o seguinte:

A Convenção constitui uma poderosa suplementação à estrutura internacional dos direitos humanos. Embora exista há apenas duas décadas, atingiu aceitação quase universal: em 2009, 
já contava com a ratificação de 193 países, com apenas duas pendências: Somália e Estados Unidos, sendo que ambos já haviam indicado seu apoio ao assinar o tratado. A influência da Convenção e seus Protocolos Facultativos já se espalha através de continentes e regiões, países e comunidades, e permanecerá claramente como a Carta Magma da Criança pelas próximas décadas- possivelmente até mesmo pelos próximos séculos. (UNICEF, 2009, p. 2),

Como nos mostra Barroso (2000, p. 83 apud FIUZA; SILA; SONEGO, 2010, p. 85), o resultado da Convenção sobre os Direitos da Criança e dos Adolescentes foi a aplicação de seus princípios em vários países, sendo aplicados [...] por mais de $96 \%$ dos países, que se tornaram obrigados por lei a tomar todas as medidas adequadas determinadas pela própria Convenção, para dar assistência aos pais ou responsáveis no cumprimento das obrigações perante suas crianças.

De todos os tratados de direitos humanos e instrumentos legais em favor da promoção e da proteção dos direitos da criança, esse é o mais completo, segundo a Unicef. E, ainda:

\begin{abstract}
Embora existam dispositivos em defesa dos direitos da criança em outros instrumentos internacionais de direitos humanos, a Convenção [essa] é o primeiro a articular todos os aspectos de direitos que são relevantes para a criança- econômicos, sociais, culturais e políticos. Foi também o primeiro instrumento internacional a reconhecer explicitamente que a criança é um ator social e detentora ativa de seus próprios direitos (UNICEF, 2009, p. 2).
\end{abstract}

A Convenção de 1989, em relação às declarações internacionais anteriores, inovou não só pela extensão, mas porque reconhece à criança (até os 18 anos) todos os direitos e liberdades inscritas na Declaração dos Direitos Humanos. Ou seja, pela primeira vez, outorgaram-se à criança e aos adolescentes direitos de liberdades, até então reservados aos adultos (ROSEMBERG; MARIANO, 2010, p. 699).

Porém, a Convenção de 1989 reconhece, também, a especificidade da criança, adotando concepção próxima à do preâmbulo da Declaração dos Direitos da Criança de 1959: "a criança, em razão de sua falta de maturidade física e intelectual, precisa de uma proteção jurídica apropriada antes e depois do nascimento" (ROSEMBERG; MARIANO, 2010, p. 699).

A convenção compreende 54 artigos e compreende fundamentalmente quatro princípios básicos: a não discriminação; o melhor interesse da criança; o direito à vida, à sobrevivência e ao desenvolvimento; o respeito pelas opi- 
niões da criança. Ao longo das duas últimas décadas, a Convenção transformou o modo como a criança era vista e tratada em todas as partes do mundo. Exerceu uma influência ampla e profunda em legislações nacionais e internacionais, em políticas e programas, em instituições públicas e privadas, nas famílias, nas comunidades e nos indivíduos. E apoiou avanços notáveis nas condições de sobrevivência, no desenvolvimento, na proteção e na participação da criança do mundo (UNICEF, 2009, p. 1).

Apesar dos inúmeros desafios que ainda não foram vencidos, a Convenção oferece uma visão de um mundo no qual todas as crianças sobrevivem e se desenvolvem, e no qual são protegidas, respeitadas e estimuladas a participar nas decisões que as afetam. Essa visão promove um mundo de paz, tolerância, equidade, respeito pelos direitos humanos e responsabilidade compartilhadaem poucas palavras, um mundo para crianças (UNICEF, 2009).

Importa referir que existem dois Protocolos Facultativos que complentam esta Convenção. O primeiro é o Protocolo Facultativo sobre Venda de Crianças, Prostituição Infantil e Pornografia Infantil, que entrou em vigor a 18 de Janeiro de 2002. Segundo a Unicef (2009), esse Protocolo foi elaborado para fortalecer a proteção da criança contra essas formas de exploração. Seus dispositivos incluem recomendações sobre a criminalização dessas práticas; procedimentos para extradição de pessoas condenadas por esses crimes; apelos para cooperação internacional em relação ao tráfico e à condenação dos infratores; procedimento para proteção e assistência a vítimas infantis; e apelos para a conscientização pública.

O outro protocolo é o Protocolo Facultativo sobre o Envolvimento de Crianças em Conflitos Armados, que entrou em vigor em 12 de Fevereiro de 2002. Vale destacar que "esse protocolo vem solucionar a polémica em torno da Convenção sobre a idade minima de 15 anos para o envolvimento de crianças em conflitos armados, uma idade considerada por muitos países de precoce" (UNICEF, 2009, p. 7). Este protocolo Facultativo exige que os Estados-Parte pró́bam o recrutamento de menores de 18 anos de idade, que se adotem todas as medidas plausíveis para garantir que soldados menores de 18 anos alistados voluntariamente não entrem em combate, e que criminalizem o recrutamento de crianças até essa idade por parte de grupos rebeldes (UNICEF, 2009).

Por sua vez, em 1990, as Nações Unidas deu outro gigantesco passo nesta matéria de direitos das crianças. O Encontro Mundial de Cúpula pela Criança adota a Declaração Mundial sobre a Sobrevivência, a Proteção e o Desenvolvimento da Criança, assim como um plano de ação para implementá-la na década de 1990. Seguidamente, em 1999, a Organização Mundial do Tra- 
balho adota a Convenção $n^{\circ} .182$ relativa a Proibição e Ação Imediata para Eliminação das Piores Formas de Trabalho Infantil. Essa Convenção define também o conceito da criança. Para o efeito dessa Convenção, o termo criança designa toda pessoa menor de 18 anos (Artigo $2^{\circ}$. da Convenção 182 da OIT). Segundo o artigo $6^{\circ}$ desta convenção, os Estados membro devem elaborar e implementar programas de ação para eliminar, como medidas prioritárias, as piores formas de trabalho infantil.

Nesse mesmo contexto de busca de soluções para a eliminação de todas as formas do trabalho infantil, a OIT adota diversas proposições relativas ao trabalho infantil, e determina que essas disposições se revestissem da forma de recomendação que complemente a Convenção sobre as Piores Formas de Trabalho Infantil. Nestes termos, a OIT adota, em 10 de Junho de 1999, a Recomendação ${ }^{\circ}$. 190, designada de Recomendação Sobre a Proibição das Piores Formas de Trabalho Infantil e a Ação Imediata para a sua Eliminação.

Em 2002, a Assembleia Geral da ONU realiza uma Sessão Especial sobre a Criança, em uma reunião que, pela primeira vez, discute especificamente questões relacionadas com os direitos da criança. Centenas de crianças participam como membros de delegações oficiais, e líderes mundiais comprometemse com a defesa dos direitos da criança, por meio de um pacto denominado "Um mundo para as crianças".

Outro marco histórico sobre os direitos da criança sob a égide da ONU ficou registrado em 2007. Em 2007, cinco anos após a Sessão Especial sobre a Criança, realizada na Assembleia Geral da ONU, o acompanhamento dos desdobramentos resulta em uma Declaração sobre a criança, adotada por mais de 140 governos. A Declaração reconhece os progressos alcançados e os desafios que se mantém, e reafirma o compromisso com o pacto "Um mundo para as crianças, a Convenção e seus Protocolos Facultativos".

Nesse processo que caracterizou a história dos instrumentos legais internacionais dos direitos da criança, vale ressaltar igualmente o papel desempenhado pela UNICEF (Fundo das Nações Unidas para a Infância), uma organização criada e ligada diretamente às Nações Unidas, considerada sua subsidiária específica em matéria dos direitos da criança. Por isso, pode-se considerar que a criação da UNICEF, foi uma das grandes conquistas que as Nações Unidas tiveram nesse processo de busca de soluções para os problemas que as crianças enfrentavam no passado e continuam a enfrentar no presente.

Fundada em 1946, no começo a UNICEF tinha como fim ajudar as crianças da Europa, do Médio Oriente e da China que haviam sofrido pelos efeitos catastróficos causados pela Segunda Guerra Mundial. No entanto, a UNICEF 
viu-se obrigada a alargar a sua atuação para atender as crianças dos países pobres que enfrentavam problemas relacionados com a fome e a doença.

\title{
História dos Direitos da Criança em Moçambique
}

Antes de falarmos das considerações acerca do histórico da legislação sobre criança ou menores no país, é importante clarificar dois pontos. Um deles tem a ver com a designação dos conceitos de criança e menor. Sobre este ponto, a legislação nacional não estabelece clara distinção. Ela só define a faixa etária sobre quem deve ser considerado criança ou menor, e o termo menor, como o dissemos anteriormente, no País não tem um teor pejorativo ou ofensivo. O outro ponto tem a ver sobre o indivíduo que deve ser considerado de criança ou menor em Moçambique.

Segundo o n. ${ }^{\circ} 1$ do artigo 3 da Lei 7/2008, "considera-se criança toda a pessoa menor de dezoito anos de idade". Entretanto, segundo o n. 2 do artigo 3 da Lei 7/2008, "nos casos expressamente previstos, a presente Lei aplica-se também aos menores com mais de dezoito e menos de Vinte e um anos de idade". Em relação à definição desta baliza de idade, afirma-se o seguinte:

\begin{abstract}
No que se refere ao conceito de criança, depois de considerados vários fatores atinentes ao desenvolvimento da criança e ao estabelecido na Convenção sobre os Direitos da Criança, decidiu-se acolher a regra estabelecida no Direito Internacional, que considera criança, todo o menor de 18 anos. Entendeu-se, entretanto, que deveria estender a aplicação da Lei aos maiores de 18 e menores de 21 , sempre que tal se justifique (ISSÁ, 2008, p. 18).
\end{abstract}

Tal como no mundo, a " legislação relativa a menores em Moçambique não evolui de forma linear, tendo refletido as dinâmicas políticas, econômicas, sociais e institucionais do país" (FUMO; JOSÉ; SAMO, 2012, p. 20). Como corolário do reconhecimento dos problemas que afetam a criança, Moçambique fez, em 1979, pela resolução n'. 23/79 de 28 de Dezembro, a "Declaração dos Direitos da Criança Moçambicana", uma resposta do governo e da Assembleia Legislativa ao fato de o ano de 1979 ter sido declarado pelas Nações Unidas o ano internacional da criança (FDC, 2008, p. 13).

A Constituição de 1990 representa uma viragem no tratamento das questões relativas aos menores em Moçambique por via da lei, ao preconizar que a maternidade é dignificada e protegida; a família, a sociedade e o Estado são responsáveis pela educação, pelo desenvolvimento harmonioso e pela proteção da criança: e que a criança não pode ser discriminada, designadamen- 
te, em razão do seu nascimento, nem sujeita a maus tratos (FUMO; JOSÉ; SAMO, 2012). Vale notar que na Constituição de 1975 não fazia referência à criança ou ao menor de idade.

Com a Constituição da República de Moçambique (CRM) de 2004, consolidam-se aspectos atinentes à proteção dos direitos das crianças. Como na Constituição de 1990, a Constituição de 2004 dedica igualmente alguns artigos sobre os direitos da criança. Essa constatação confirma-se logo no artigo 40, onde se define o seguinte:

- As crianças têm direito à proteção e aos cuidados necessários ao seu bem-estar;

- As crianças podem exprimir livremente a sua opinião, nos assuntos que lhes dizem respeito, em função da sua idade e maturidade;

- Todos os atos relativos às crianças, quer praticados pelas entidades públicas, quer por instituições privadas, têm principalmente em conta o interesse superior da criança.

Posteriormente, no artigo 120, afirma-se que "a família é responsável pelo crescimento harmonioso da criança, educa as novas gerações nos valores morais, ético e socais" ( ${ }^{\circ} .2$ do artigo 120 da CRM, 2004); sobre o papel da Família e do Estado, diz-se que "a família e o Estado asseguram a educação da criança, formando-a nos valores da unidade nacional, no amor à pátria, igualdade entre homens e mulher, respeito e solidariedade social" $\left(\mathrm{n}^{\circ} .3\right.$, do artigo 120 da CRM, 2004). Seguidamente, a CRM aborda a questão da infância nos seguintes termos:

- Todas as crianças têm o direito à proteção da família, da sociedade e do Estado, tendo em vista o seu desenvolvimento integral;

- As crianças, particularmente as órfãs, as portadoras de deficiências e as abandonadas, têm proteção da família, da sociedade e do Estado, contra qualquer forma de discriminação, de maus tratos e contra $o$ exercício abusivo da autoridade na família e nas demais instituições.

- A criança não pode ser discriminada, designadamente, em razão do seu nascimento, nem sujeita a maus tratos;

- É proibida o trabalho da criança quer em idade de escolaridade obrigatória quer em qualquer outra (Artigo 121 da CRM, 2004).

É importante notar que o País alcança a independência do jugo colonial português em 1975. No entanto, só no ano de 2008 é que foram aprovadas uma série de leis, com vistas à promoção e proteção dos direitos da criança com conteúdos mais abrangentes e completos no que tange aos direitos da criança ou do adolescente. Essa demora na criação de uma legislação que 
protegesse integralmente os direitos da criança no país contribuiu significativamente para que, até agora, alguns aspectos sobre os direitos da criança não fossem devidamente salvaguardados.

Destaca-se, nessas leis aprovadas em 2008, a lei nº. 7/2008 de 09 de Ju$1 \mathrm{lho}^{3}$, que pode ser considerada como o estatuto de criança ou de menores de Moçambique, dada a significativa abrangência e à forma como articula todos os aspectos de direitos que são relevantes na promoção e proteção dos direitos da criança e do menor de idade no País. Esta lei é designada às vezes como a lei de Bases de Proteção de Criança, e em outras vezes como lei de Promoção e Proteção do Direito da Criança.

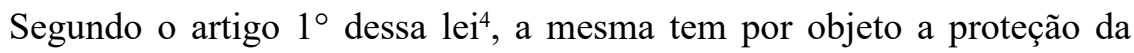
criança e visa reformar, estender, promover e proteger os direitos da criança, tal como se encontram definidos na Constituição da República, na Convenção sobre os Direitos da Criança, na Carta Africana sobre os Direitos e o Bem Estar da Criança e demais legislação de proteção à Criança. No artigo 4, sobre os direitos fundamentais, afirma-se o seguinte:

- A criança goza de todos direitos fundamentais inerentes à pessoa humana, sem prejuízo da proteção integral de que trata a presente lei, assegurando-se-lhe, através do adequado quadro jurídico e outros meios, todas as oportunidades e facilidades, afim de lhe facultar o desenvolvimento físico, mental, moral, espiritual e social, em condições de liberdade e de dignidade;

- A criança não pode ser discriminada, nomeadamente em razão da cor, raça, sexo, religião, etnia, origem de nascimento, condição socioeconómica, estado de saúde e deficiência (CRM, 2004).

No artigo 6 se estabelece um fato muito importante a ser levado em conta no que se refere aos direitos da criança, ao se dizer que nenhuma criança pode ser sujeita a tratamento negligente, discriminatório, violento e cruel, nem ser objeto de qualquer forma de exploração ou opressão, sendo punidos por lei todos os atos que se traduzam em violação dos princípios ora estabelecidos.

Igualmente fato importante se pode notar no artigo 9, referente à interpretação e aplicação, ao se prever o seguinte:

- Na interpretação da presente lei deve ter-se em conta os superiores interesses da criança, os fins sociais a que ela se dirige, as exigências do bem comum, os direitos e deveres individuais e coletivos e a condição

3 A definição do conceito de criança consta nesta lei.

$4 \quad$ Lei ${ }^{\circ}$. 7/2008 de 09 de Julho. 
especial da criança como pessoa em desenvolvimento;

- Em caso de existir norma legal menos protetora ou menos promotora dos direitos da criança, sobrelevam sempre os princípios e as disposições da presente Lei;

- Para efeitos da presente Lei, entende-se por superior interesse da criança tudo o que tem a ver com a defesa e salvaguarda da sua integridade, identidade, manutenção e desenvolvimento são e harmonioso (CRM, 2004).

Na Lei ${ }^{\circ} 7 / 2008$ de 09 de Julho também se definem os direitos e deveres da criança. Igualmente, trata-se, nessa Lei, das medidas de proteção, incluindo situações de criança ou menores em conflito com a lei e medidas socioeducativas. Como havíamos dito anteriormente, em 2008, foram aprovadas uma série de leis sobre a promoção e proteção dos direitos da criança. Aprovou-se igualmente, nesse ano, a Lei ${ }^{\circ}$. 08/2008, designada Lei da Organização Jurisdicional de Menores, de 15 de Julho. Segundo informações disponíveis, “Até o presente momento, o direito processual referente à jurisdição de menores achava-se contido, essencialmente, no Estatuto de Assistência Jurisdicional de Menores, aprovado pelo Decreto $n^{\circ}$. 484/71, de 08 de Novembro" (ISSÁ, 2008, p. 69). Ainda, o autor fazendo referências a estes dois instrumentos legais, por ele mencionados, afirma o seguinte:

\begin{abstract}
Os dois instrumentos legais acima mencionados encontravamse, em muito dos seus aspectos ultrapassados e desajustados à realidade. Por outro lado, em muitas vertentes, o Estatuto e seu Regulamento não chegaram a ter qualquer aplicação prática, designadamente, no que dissesse respeito aos serviços de assistência social, de observação e aos estabelecimentos de prevenção criminal previstos no Estatuto e Regulamento. Na verdade, aqueles serviços e instituições nunca chegaram a funcionar tal como foram concedidos (ISSÁ, 2008, p. 69).
\end{abstract}

A recente entrada em vigor da Constituição da República de Moçambique, da Lei $\mathrm{n}^{\circ}$. 10/2004, de 25 de Agosto, da lei da Família, aprovada pela Lei $n^{\circ}$. 10/2004, de 25 de Agosto, do Código de Registo Civil, aprovado pela Lei $\mathrm{n}^{\circ}$. 12/2004, de 08 de Dezembro, tornaram também imperiosa e inadiável a revisão do Estatuto de Assistência Jurisdicional de Menores (ISSÁ, 2008, p. 69). Mais adiante, sobre essa reforma da jurisdição de menores afirma-se o seguinte:

Com esta reforma cremos que se eliminarão ou se reduzirão, de forma substancial, não só vazios de lei, como também as dúvidas que se suscitavam na interpretação e aplicação das nor- 
mas processuais respeitantes a menores, quer na vertente de sua recuperação (menores em conflito com a lei), quer na vertente de proteção. E, com a introdução de novas formas de proteção, ficam melhor salvaguardados os superiores interesses da criança moçambicana (Ibid., p. 72).

Sobre objeto e fins da jurisdição de menores, preceitua-se que a jurisdição de menores tem por objeto e finalidades de garantir a assistência aos menores no domínio da prevenção criminal, mediante aplicação de medidas de proteção, assistência ou educação e no domínio da defesa dos seus direitos ou interesses, mediante a adoção de providências cíveis adequadas (Artigo 1 da lei $n^{\circ} .8 / 2008$ ).

E, ainda em 2008, aprovou-se a Lei n ${ }^{\circ} .6 / 2008$, de 09 de Julho, Lei sobre o Tráfico de Pessoas. Essa lei tem por objeto estabelecer o regime jurídico aplicável à prevenção e combate ao tráfico de pessoas, em particular mulheres e crianças, nomeadamente a criminalização do tráfico de pessoas e atividades conexas e a proteção das vítimas, denunciantes e testemunhas. Igualmente existe no país a lei da família que também prevê a proteção dos direitos das crianças, como podemos constatar na alínea c), artigo $4^{\circ}$, sobre um dos deveres da família: "garantir o crescimento e desenvolvimento integral da criança, do adolescente e do jovem".

Em Moçambique, encontramos ainda outras leis que tratam acerca dos direitos das crianças, sendo de destacar a nova lei do trabalho, a Lei $n^{\circ}$. 23/2007, de 01 de Agosto, que traz consigo alguns preceitos legais sobre as medidas que os empregadores devem adotar, no sentido de proporcionar ao menor condições de trabalho adequadas a sua idade, saúde, segurança, educação e formação profissional, prevenindo quaisquer danos ao seu desenvolvimento físico, psíquico e moral e outros aspectos inerentes ao menor no âmbito da legislação laboral; a Lei de Interdição ao acesso de Menores a Clubes Noturnos e o Código Penal.

Podemos destacar igualmente alguns documentos que foram criados com o fim de assegurar a proteção dos direitos da criança, como o Plano Nacional de Ação para a Criança, Estratégia da Ação Social para a Criança, e Plano de Ação para as Crianças Órfãs e Vulneráveis aprovados em 2006. Vale notar igualmente o Decreto 08/2008, de 31 de Março, que cria o Conselho Nacional dos Direitos da Criança, resultante da exigência imposta pela Lei $n^{\circ} .7 / 2008$ de 09 de Julho. Essa Lei de Promoção e Proteção do Direito da Criança, no seu artigo 71, remetia ao Governo a competência de regulamentar a composição, funcionamento e competência do Conselho Nacional dos Direitos da Criança, fato concretizado com a criação e aprovação des- 
te decreto. Esse Conselho tem como objetivos supervisionar, impulsionar e acompanhar a implementação de políticas e programas aprovados pelo governo na área da criança.

Sobre os instrumentos internacionais que asseguram a proteção dos direitos da criança, importa referir que Moçambique ratificou uma boa parte desses instrumentos, destacando-se a Convenção das Nações Unidas Sobre os Direitos da Criança, ratificada pela Resolução n ${ }^{\circ}$. 19/90, de 23 de Outubro; a Carta Africana dos Direitos e Bem-estar da criança adotada pelos Estados africanos, membros da OUA (Organização da Unidade Africana), agora UA (União Africana), ratificada através da Resolução n . 43/2002 de 28 de Maio; a Convenção $n^{\circ} .138$, sobre a idade mínima de admissão ao emprego, de 1973 no contexto da prossecução dos objetivos da Organização Internacional de Trabalho (OIT), ratificada através da Resolução $n^{\circ}$. 5/2003 de 23 de Abril e a Convenção $\mathrm{n}^{\circ}$. 138, relativa à interdição das Piores Formas de Trabalho das Crianças e à ação imediata com vista à sua eliminação, ratificada pela Resolução $n^{\circ}$. 6/2003, de 23 de Abril.

\section{Considerações finais}

Este estudo sobre o processo da evolução da história dos direitos da criança demonstra claramente que nem sempre a sociedade deu atenção especial à criança. Esse fato foi mais visível por volta do século XII.

De outro modo, o estudo demonstrou que o século XX foi o século da descoberta da criança como um sujeito de direitos porque, foi a partir de então que se deu um grande impulso na matéria de promoção e proteção dos direitos da criança. Neste aspecto, os Estados Unidos da América foram os primeiros a promover uma reforma radical na assistência judiciária ao menor, por meio da instituição do julgamento de crianças em tribunais especiais.

Importa salientar que o processo da evolução da historia dos direitos da criança no mundo, no geral, e em Moçambique, em particular, não decorreu de forma fácil e linear. Houve, ao longo do processo, muitos debates e tensões, com avanços e recuos. Vale salientar ainda, como ficou demonstrado no estudo, o papel desempenhado pela ONU e outras ONGs internacionais, e por outros estudiosos e sociedade civil que, de forma direta, contribuíram para a criação e aprovação de vários instrumentos internacionais que versam acerca da temática de criança. No que concerne aos estudiosos, se destaca a publicação do livro de Philippe Ariès, em 1961, intitulada L'enfant et La vie familiale sou l'ancien régime». 
No caso de Moçambique, em particular, se destacam as mudanças constitucionais que tiveram lugar com a aprovação da CRM de 2004, que contribuíram significativamente para a melhoria dos direitos da criança.

\section{Referências}

ARIÈS, Philippe. História social da criança e da família. Trad. de Dora Flaksman- 2.ed.-Rio de Janeiro: LTC, 1981.

CARVALHO, Eronilda Maria Góis. Educação infantil: percurso, dilemas e perspectivas. Ilhéus, BA: Editus, 2003.

ISSÁ, Abdul Carimo Mahomed. Lei de Base de Proteção da Criança, Lei da Organização Jurisdicional de Menores e Lei Sobre o Tráfico de Pessoas. Maputo: Central Impressora e Editora de Maputo, 2008.

FDC-FUNDAÇÃO PARA O DESENVOLVIMENTO DA COMUNIDADE. Violência Contra Menores em Moçambique: revisão de literatura. Maputo: KULA- Estudos e pesquisas Aplicadas, Ltda, 2008.

FIUZA, Solange C. R.; SILA, Renilson José da; SONEGO, Cristiane. Uma reflexão acerca dos direitos fundamentais da criança e do adolescente na região de Guarapuava-PR. In: SILVA, Paulo Vinícius Baptista da; PASCHOALICK, Rosele Ciccone; LOPES, Jandicleide Evangelista. (Org.) Crianças e adolescentes: estudo sobre direitos violados nas microrregiões do Paraná. Curitiba: Secretaria de Estado da Criança e da Juventude, Universidade Federal do Paraná, 2010. p. 84-94.

FUMO, Joaquim; JOSÉ, André Cristiano; SAMO, Atanásio Saturnio. Estudo Diagnóstico da Justiça de Menores. Maputo: CEIDIMA, 2012.

LIVEN, Esteban. A infância em cena- Constituição do sujeito e desenvolvimento psicomotor. Petrópolis, Rio de Janeiro: Vozes, 1997.

MOÇAMBIQUE. Constituição (2004). Constituição da República de Moçambique, de 16 de Novembro de 2004.Boletim da República- BR, Maputo, 22 de Dezembro de 2004, I Série- Número 51 .

OIT-ORGANIZAÇÃO INTERNACIONAL DO TRABALHO. Convenção Sobre a Proibição das Piores Formas de Trabalho Infantil e a Ação Imediata para a sua Implementação, [S.1], 1999.

ONU-ORGANIZAÇÂO DAS NAÇÕES UNIDAS. Declaração Universal dos Direitos Humanos, [S.I], 1948.

Pacto Internacional sobre Direitos Civis e Políticos, [S.I], 1976a.

. Pacto Internacional de Direitos Econômico, Sociais e Culturais, [S.I]. 1976 b.

RENAUT, Alain. A Libertação das Crianças: a era da criança cidadão. Lisboa: Instituto Piaget, 2002. 
RIBEIRO, Viviane Dias. A Situação Comteporânea da Criança e dos Direitos no Contexto das Relações Internacionais. 2011, n. 44f. Dissertação (Especialização em Relações Internacionais), Programa de Pós-Graduação da Casla - Casa Latino-Americana de Curitiba, 2011.

(Mestrado em Relações Internacionais) - Curso de Pós- Graduação em Relações Internacionais da Universidade Federal do Paraná (UFPR), Curitiba, 2011.

ROSEMBERG, Flávia; MARIANO, Carmen Lúcia Sussel. A Convenção Internacional sobre os Direitos da Criança: debates e tensões. Caderno de Pesquisa. São Paulo, v .40, n. 141, p. 693-728, set./dez. 2010.

SARTÓRIO, Alexsandra Tomazelli. Adolescente em Conflito com a Lei: uma análise dos discursos dos operadores jurídico-sociais, 2007, n. 304 f. Dissertação (Mestrado em Política Social) - Curso de Pós- Graduação da Universidade Federal do Espírito Santo, Vitória, 2007.

SILVA, Gustavo de Melo. Adolescente em conflito com a lei no Brasil: da situação irregular à proteção. Revista Brasileira de História \& Ciências Sociais.[S.I],v. 3, n. 5, p. 33-43, jul. 2011.

UNICEF - FUNDO DAS NAÇÕES PARA A INFÂNCIA. Situação Mundial da Infância. 2009 Disponível em: < http://www.unicef.org/brazil/pt/sowc_20anosCDC.pdf $>$ Acesso em: $17 \mathrm{de}$ abr. 2016.

Agência de fomento: CNPQ.

Submissão em: 23/01/2015

Revisão: 09/03/2016

Aceite em: 06/03/2016

Tomás Xavier José Francisco é mestre em Ciências Sociais Aplicadas na área de Cidadania e Políticas Publicas pela Universidade Estadual de Ponta Grossa (UEPG) e graduado em Ciências Policiais pela Academia de Ciências Policiais de Moçambique (ACIPOL).

Endereço para correspondência: Direção de Pessoal e Formação do Comando Provincial da Polícia República Moçambique (PRM)-Tete, Avenida Eduardo Mondlane, 227, Cidade de Tete-Moçambique E-mail: tomasxavier.j@gmail.com 